\title{
Paper 17 of 18
}

\section{The Ecology and Biting Activity of Blackflies (Simuliidae) and the Prevalence of Onchocerciasis in an Agricultural Community in Ghana}

\author{
A. A. Opoku \\ CSIR-Water Research Institute, P. O. Box AH 38, Achimota, Ghana \\ E-mail: aanimpoku@yahoo.com
}

\begin{abstract}
Field studies on the ecology and biting activity of blackflies (Simuliidae), as well as an assessment of the prevalence status of Onchocerciasis diseases were conducted in a rural forest area of Ghana. It was observed that the blackfly vector Simulium damnosum s.l was the most abundant and widely distributed of the species encountered. The $p \mathrm{H}$ and flow rate of the breeding sites were significant factors influencing the distribution of the flies. The pattern of biting exhibited by S. damnosum s.l was bi-modal with morning and late afternoon peak activity. The savanna forms of the S. damnosum s.l were found to occur in the area representing 0.0 $0.26 \%$ of the catch. The disease is endemic with the prevalence rate ranging between 0.0001 and $12.9 \%$ in the district and the frontline communities having infection rates exceeding $60 \%$.
\end{abstract}

\section{Introduction}

Onchocerciasis or river blindness is a major tropical parasitic disease which affected 1.5 million people with 128,000 blind in the River Volta basin prior to the launching of the World Health Organisation (WHO) sponsored Onchocerciasis Control Programme (OCP) in 1974 (Anon.,1985). It causes ocular complications, blindness, lesions and severe disabling itching (Anon., 1985). It is known to be responsible for the mass desertion of people from the fertile riverine valleys in some parts of Northern and Upper regions of Ghana.

The disease is caused by a nematode worm Onchocerca volvulus and is transmitted to humans through the bite of the blackfly Simulium damnosum s.l, a complex of sibling species originally comprising S. damnosum s.s., S. sirbanum, S. sanctipauli, S. soubrense, S. yahense and S. squamosum (Dunbar \& Vajiime, 1972; Vajime \& Dunbar, 1975) but now known to include other species such as $S$. leonense, S. konkourense and $S$. dieguerense (Boakye, 1993; Boakye et. al., 1993). The disease tends to vary in severity in different ecological zones with the vectors differing also accordingly (Le Berre et al., 1964; Le Berre, 1966; Disney \& Boreham, 1969). Hence, the division of the S. damnosum s.l into forest and savanna types.

The Onchocerciasis Control Programme (OCP), which ran from 1974-2000 in the Volta basin, had the objective of eliminating Onchocerciasis as a disease of public health and socio-economic importance in the basin. Though the OCP was a success in the River Volta basin, a largely savanna zone, the control of the disease in the forest areas of Ghana has not received the deserved attention. In the light of this, a survey was initiated on the blackfly and the disease in some forest areas of Ghana in 1996 and the information obtained documented (Opoku, 1997, 2000).

The paper looks at the blackfly's ecology and biting activity, as well as the epidemiology of the disease in the Twifu-Heman Lower Denkyira District, a forest area with one of the largest oil palm plantations and oil mill in Ghana. The study covered the period 2003-2004.

Study area

\section{Materials and methods}

The district, Twifu-Heman Lower Denkyira (Fig. 1) is located between latitude $5^{\circ} 15^{\prime} \mathrm{N}$ and $5^{\circ} 51^{\prime} \mathrm{N}$ and longitude $1^{\circ} 15^{\prime} \mathrm{W}$ and $1^{\circ} 45^{\prime} \mathrm{W}$. It has total areas of $1,199 \mathrm{~km}^{2}$, and lies within the wet semi-equatorial zone with a mean annual rainfall of $175 \mathrm{~cm}$. It has a fairly high temperature of $26-33{ }^{\circ} \mathrm{C}$ and a high relative humidity of $75-80 \%$. The major river draining the area is the River Pra and the mainstay of the economy is crop farming and mineral exploitation. The district is divided into four sub-catchments, namely Twifu Prasu, Heman, Mokwa and Jukwa. 


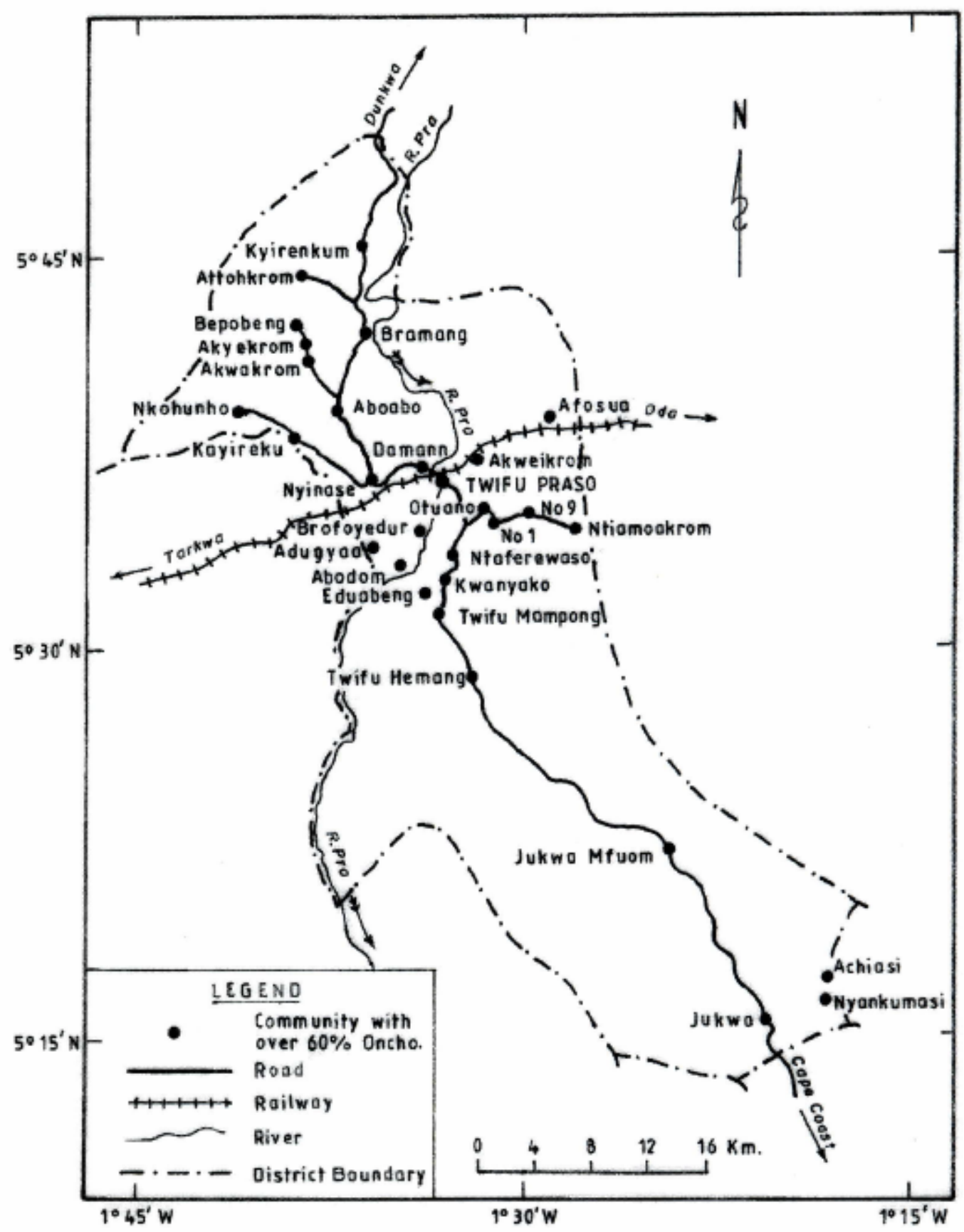

Fig. 1. The map of the district showing first line communities with over $60 \%$ Onchocerciasis infection rate

Prospection for pre-adult stages of the Simuliidae

Eggs, larvae and pupae were prospected for in the fast flowing sections of the river with adequate substratum during the wet season (May-August) and the dry season (January-April). Collected samples were examined and identified using the keys of Freeman \& De Meillon (1968) and preserved in 80\% alcohol. Empty pupal cases were also collected, identified and recorded as a measure of adult emergence. All larvae collected were identified to separate the vectors from non-vectors. At each identified breeding site, the $p \mathrm{H}$ and flow rate of the river were recorded with a $p \mathrm{H}$ meter and a flow meter, respectively. The dissolved oxygen (DO) concentration of the sites was also determined using the wrinkler method of analysis (APHA, 1997).

Collection of man-biting adult blackflies 


\section{West Africa Journal of Applied Ecology (WAJAE) -ISSN: 0855-4307 \\ Volume 9 (Jan - Jun 2006) \\ www.wajae.org}

Adult female flies were captured along the banks of the River Pra in openings on oil palm plantations, on farms and around settlements at Eduaben and Brofoyedru townships. The collection of the adult flies was undertaken by 10 recruited flycatchers posted at these selected checkpoints in Brofoyedur and Eduaben, respectively. The adult fly collection was carried out during the dry season (January-April) and the wet seasons (May-August) in 2004. Female S. damnosum s.l adults were collected into glass vials when the flies attempted to bite them below the knees for a blood meal. Collection was conducted between 07.00 and 18.00 $\mathrm{h}$ for 3 consecutive days a month.

Catches were examined morphologically and the members of the savanna group (S. damnosum s.s., S. sirbanum) separated according to criteria described by Garms \& Cheke (1985) and through personal knowledge.

\section{Epidemiological assessment}

The disease prevalence was determined using data obtained from the skin snip method. This method involved the cutting of skin on the buttocks or backs of a person and examining it under the microsope for the presence or absence of microfilariae of Onchocerea volvulus.

\section{Distribution of pre-adult species of the Simuliidae}

\section{Results and discussion}

The pre-adult stages of the Simulium species occurrence and distribution during the wet season are shown in Table 1. Three species of the Simuliidae, S. adersi, S. damnosum s. l. and S. unicornutum were found to occur in the areas prospected. The $S$. damnosum s.l., the complex of species responsible for the transmission of the onchocerciasis diseases, were the most abundant and widely distributed of the species present.

TABLE 1

$\mathrm{pH}$, flow rate and species of Simulium

\begin{tabular}{|c|c|c|c|}
\hline $\begin{array}{l}\text { Location } \\
\text { River/Town }\end{array}$ & Species identified & $\mathrm{p} H$ & Flow rate $\left(\mathrm{ms}^{-1}\right)$ \\
\hline Pra/Tofoi & $\begin{array}{l}\text { S unicornutum } \\
\text { S. damnosum s.l. }\end{array}$ & 6.4 & 2.8 \\
\hline R. Ongwa/Bimponso & S. damnosum s.l. & 6.2 & 2.6 \\
\hline R. Bimpon/Bimpon & $\begin{array}{l}\text { S. adersi } \\
\text { S. damnosum s.l. }\end{array}$ & 7.1 & 2.9 \\
\hline R. Aduano/Nuamakrom & S. damnosum s.l. & 6.1 & 2.4 \\
\hline R. Ongwa/Nuamakrom & $\begin{array}{l}\text { S. damnosum s.l. } \\
\text { S. adersi }\end{array}$ & 6.4 & 2.7 \\
\hline R. Pra/Bukura & $\begin{array}{l}\text { S. damnosum s.l. } \\
\text { S. adersi }\end{array}$ & 7.2 & 3 \\
\hline R. Wurowuro/Daman & $\begin{array}{l}\text { S. unicornutum } \\
\text { S. damnosum s.l. }\end{array}$ & 6.7 & 2.4 \\
\hline
\end{tabular}

The pre-adult stages of the species were found to occur on rock surfaces, trailing leaves, stems, etc., which were about $5 \mathrm{~cm}$ below the water surface. Rocks with algal colonization did not appear to favour the breeding of any stage of the Simuliids and this could be a distribution limiting factor considering the preponderance of algae in many parts of the river system. The vectors, S. damnosum s.l. species, occurred on sub-strates in both the open and shaded portions of the river and light could not be considered an inhibiting factor in the distribution. The mean dissolved oxygen concentration recorded at each breeding site was more than $60 \%$ saturation, a factor crucial to the breeding of the flies.

S. adersi and S. unicornutum, which are non vectors, were the main competitors for the occupation of the substrates. S. adersi was invariably found to occur in almost equal numbers as the vectors wherever there was a sympatric occurrence. This could be due to its highly adaptable nature as it is also recorded to be common in the River Volta basin (Anon., 1985). The pre-adult species were more abundant and widely distributed in the 


\section{West Africa Journal of Applied Ecology (WAJAE) -ISSN: 0855-4307 \\ Volume 9 (Jan - Jun 2006) \\ www.wajae.org}

wet season than in dry season. The abundance and pattern of larval and pupae distribution during the wet and dry seasons showed that the rains influence greatly their numbers and distribution. The rains cause an increase in the mean current speed and the nutritive status of the river leading to an expansion of larval breeding sites with a consequent increase in larval numbers and hence population.

\section{Ecological factors}

The flow rate and $p \mathrm{H}$ of the water, important factors in the distribution of the pre-adult flies, were recorded to be between 2.4 and $3.0 \mathrm{~ms}^{-1}$ and 6.1-7.2 at breeding sites, respectively (Table 1). Vectorial species are known to prefer currents of $0.7-2 \mathrm{~ms}^{-1}$ but have been found also to occur in currents ranging from $0.1-2.5 \mathrm{~ms}^{-1}$ (Anon., 1985, Grunewald, 1981). According to Gersabeck \& Merrit (1979), the speed of the current is probably the key factor in determining the micro distribution of most species of larvae in a stream.

The $p \mathrm{H}$ value obtained suggests that the $S$. damnosum s. l. could occur in both acidic and alkaline environments. S. squamosum and S. yahense, both members of $S$. damnosum s.l. are known to populate watercourses with acidic $p \mathrm{H}$ whereas the other species are found in more alkaline environments (Anon., 1985). This suggests that $p \mathrm{H}$ could be a limiting factor in the distribution of the larval species.

The $p \mathrm{H}$ of the river depended on the type of rocks and soils in the catchment and on the decayed vegetation cover. The $p \mathrm{H}$ status of the River Pra and its tributaries is, however, periodically affected by the sediment load released into the river from the alluvial dredging of River Offin, which joins River Pra. The sediment loads and the decayed vegetation cover tend to reduce the dissolved oxygen concentrations required for the breeding of the Simuliidae, therefore affecting the numbers and types of flies during certain periods of the year.

\section{Adult fly: seasonal variation}

Adult blackflies were caught at all the ten selected checkpoints. The flies caught varied in numbers and in the daily distribution pattern depending on a host of ecological factors but, more importantly, was the temperature of the day and the proximity of the breeding sites to the collection points. Fig. 2 shows the pattern of distribution and biting of the flies daily in Eduaben and Brofoyedur catchment areas, respectively, in the wet season in 2004. An analysis of variance (ANOVA) treatment of the mean number of flies biting daily during the wet season showed significant differences in the first $4 \mathrm{~h}$ and last $4 \mathrm{~h}$ at both.

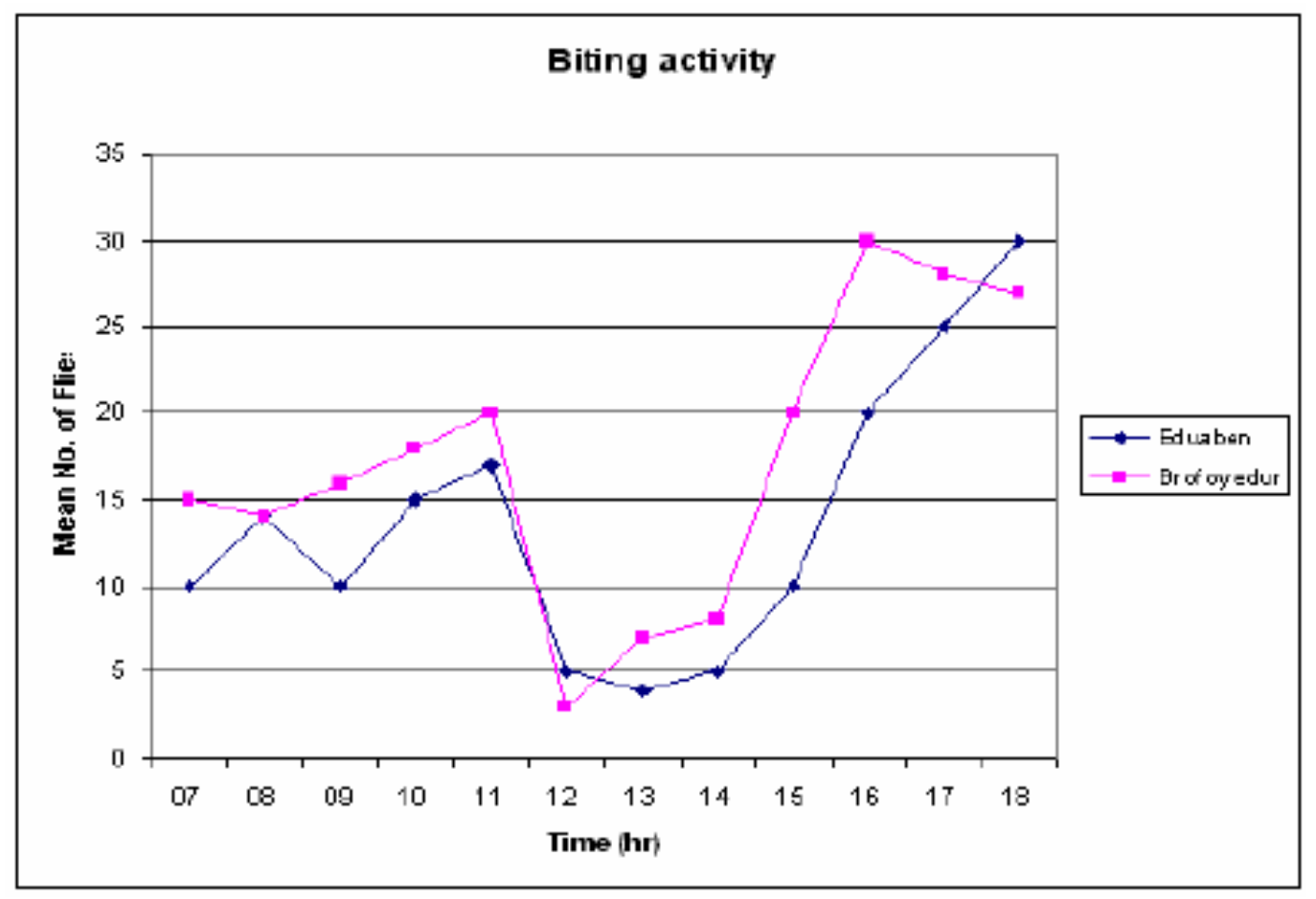




\section{West Africa Journal of Applied Ecology (WAJAE) -ISSN: 0855-4307 \\ Volume 9 (Jan - Jun 2006) \\ www.wajae.org}

Fig. 2. The mean daily biting pattern of Simulium damnosum s.l. in the The Brofoyedur and Eduaben areas.

Biting activity of flies appeared to increase with increasing temperature $\left(24-28{ }^{\circ} \mathrm{C}\right)$ from 7 to $11 \mathrm{~h}$ until attainment of peak activity at $11 \mathrm{~h}$ (Fig. 2). Activity, thereafter, declined from 12 to $15 \mathrm{~h}$ when temperature exceeded $30{ }^{\circ} \mathrm{C}$. Activity rose again with subsequent fall in temperature in the late afternoon $(>15 \mathrm{~h})$. The daily biting pattern hampers farm-ing activities in the area since the active fly biting period (morning and late afternoon, Fig.1) coincides with the active farming period in the areas. Farmers are therefore more predisposed to receiving repeated bites and therefore more prone to contracting the disease.

Table 2 shows the dry and wet seasons collections at Eduaben and Brofoyedur respectively for the year 2004.

TABLE 2

Dry and wet seasons collections at Eduaben and Brofoyedur

$\begin{array}{lll}\begin{array}{l}\text { Season } \\ \text { Eduben }\end{array} & \begin{array}{l}\text { Total No. } \\ \text { of flies caught }\end{array} & \begin{array}{l}\text { No. of savanna } \\ \text { forms of flies }\end{array} \\ \begin{array}{l}\text { Dry } \\ \text { Wet }\end{array} & 4200 & 2(0.05 \%) \\ \text { Brofoyedur } & 6600 & 0(0 \%) \\ \text { Dry } & & \\ \text { Wet } & 3520 & 9(0.26 \%) \\ & 8290 & 2(0.024 \%)\end{array}$

The numbers obtained showed that there is a perennial production of flies throughout the year and, therefore, the farmers are exposed to biting throughout the year. An ANOVA treatment of the mean number of flies biting during the wet and dry seasons showed significantly higher numbers during the wet season than in the dry season at $(\mathrm{P}<0.05)$.

The savanna forms of the flies constituted $0 \%-0.024 \%$ of the catches in the wet season and $0.05 \%-0.26 \%$ of the catches in the dry season. Though the numbers of the savanna forms are relatively low, the incursion of the savanna forms into a forest area is dangerous because its more virulent blinding forms of the disease could soon be prevalent in the area where hitherto only the benign forest forms of the disease exist. There is a school of thought, which suggest that the incursion of the flies is related to the massive deforestation, which allows the creation of conducive environment neces-sary for their survival. Wilson et al. (2002) showed that the savanna forms of S. damno-sum s.l. have been occurring in southern Ghana including Twifu Prasu, and there is the likelihood that theses incursions of S. sirbanum and S. damnosum s.s. are related to deforestation.

An ANOVA treatment of the mean numbers of flies collected at the various check-points indicated that a signifi-cantly higher numbers of flies $(\mathrm{P}<0.05)$ were caught at checkpoints located close to river courses than in other areas and this reinforces the assertion that the distance of a breeding site from the settlements, farms, etc. is a determinant in the distribution of the adult flies. It was observed that the population dynamics of the flies in the area correlated with the seasonality of the area, hence, the numbers, distribution and intensity of biting of the flies were dependent more on the rainfall pattern and temperature.

\section{Onchocerciasis prevalence}

Table 3 shows the disease prevalence for the years 1993, 1994, 1995 and 1996 in the Jukwa, Heman, Praso and Mokwa, sub- catchment areas of the district. Table 4 also shows the prevalence rates for the years 2001, 2002 and 2003 in the District. The prevalence rates were established from clinical data (District Health Management Records, Twifu Praso). 


\section{West Africa Journal of Applied Ecology (WAJAE) -ISSN: 0855-4307 \\ Volume 9 (Jan - Jun 2006) \\ www.wajae.org}

Onchocerciasis prevalence in the sub-catchment areas

$\begin{array}{llll}\text { Jukwa Hemang Praso Mokwa } & \text { Pro }\end{array}$

1993

No. of people

reported sick

No.infected with

1022

2454

23739

5961

Oncho (\%)

$92(9 \%)$

204(8\%)

$1,068(4.5 \%)$

$70(1.2 \%)$

1994

No. of people

reported sick

No. infected with

$(-)$

2648

2745

6144

Oncho (\%)

$(-)$

$5(.02 \%)$

269(9.8\%)

183(3\%)

1995

No. of people

reported sick

No. infected with

$(-)$

3078

28,435

8,335

Oncho (\%)

$(-)$

11(0.36\%)

237(0.83\%)

$239(2.87 \%)$

1996

No. of people

reported sick

No. infected

with oncho (\%)

$(-)$

$(-)$

9070

3031

(-) Non-availability of data

(-)

$(-)$

$54(0.6 \%)$

131(4.3\%)

TABLE 4

Rates of Onchocerciasis prevalence in the sub-catchment areas

$\begin{array}{lclc}\text { Year } & 2001 & 2002 & 2003 \\ \begin{array}{l}\text { No. of people } \\ \text { reported sick }\end{array} & 7895 & 23548 & 2834 \\ \begin{array}{l}\text { Number infected } \\ \text { with Oncho (\%) }\end{array} & 83(.0001 \%) & 3038(12.9 \%) & 99(3.5 \%)\end{array}$

The prevalence rates of the disease in the area show that the District is Onchocerciasis endemic. The percentages of people infected with the disease appear to be low and this could be due to effectiveness of the free mass distribution of the Onchocerciasis drug, Ivermectin, within the communities for the last 10 years.

The level of severity of the disease, however, varied from place to place depending on a number of factors, namely (i) the location of the community, (ii) the size of population, and (iii) the occupational practices of the inhabitants. A classical example is a small frontline farming community at Brofo-yedur where infection rate exceeds 60\%. (Fig. 2). Fig. 2 shows first line communities and the effect of the disease on these communities. They appear to be the worst affected with infection rates ranging over $60 \%$ within the communities. These com-munities are exposed to repeated daily bites and are, therefore, subjected to increased rate of infection, making them more vulnerable than settlements farther away from the breed-ing sites. The risk of the disease, therefore, increases with proxi-mity to the breeding sites, a phemenon generally recognised.

The effect of the disease due to the occupational practices is evidently illustrated among the farm workers at Twifu Oil Palm Plantation Company (TOPPS). In 1989, out of 1722 plantation workers tested for the Onchocerciasis disease $84 \%$ proved positive. In a similar exercise in 1992, out of 775 workers tested $38.6 \%$ proved positive. These attest to the fact that the farming practices also expose them to repeated bites with 


\section{West Africa Journal of Applied Ecology (WAJAE) -ISSN: 0855-4307 \\ Volume 9 (Jan - Jun 2006) \\ www.wajae.org}

consequent increases in infection. Since farming practices are not mechanised the contact time with the vectors in the field are relatively longer and increase the risk level of contracting the diseases.

As a result of the disease the very social fabric of the society is at risk. The detection of the disease among the population shows that the management of the disease in terms of rapidity of diagnoses is good. However, the disease preventive practice within the catchment is an issue worth addressing vigorously. Therefore, the information on the occurrence and biting activity of black flies, as well as the prevalence of the diseases has implication for planning control.

\section{Acknowledgement}

The author is grateful to the Twifu-Heman Lower Denkyira District Health Management Team for assistance in data collection, and also to the CSIR-Water Research Institute for facilitating this study. Thanks to Dr Samman for proof reading and Dr Biney for his encouragement.

\section{References}

Anon. (1985). Ten years of Onchocerciasis Control Programme in West Africa. Review of the works of Onchocerciasis Control Programme in the Volta River basin area from 1974-1984. (OCP/GVA/85.13).

APHA (1997). Standard Methods for the Examination of Water and Waste Water, 16th edn. Washington D.C.

Boakye D. A. (1993). A pictorial guide to the chromosomal identification of members of the Simulium damnosum Theobald complex in West Africa with particular reference to the Onchocerciasis Control Programme area. Trop. Med. Parasitol. 44: 223-224.

Boakye D. A., Post R. J., Mosha F. W., Surtees D. P. and Baker R. H. A. (1993). Cytotaxonomic revision of the Simulium sanctipauli subcomplex (Diptera: Simuliidae) in Guinea and the adjacent countries including descriptions of two new species. Bull. entomol. Res. 83: 171-186.

Disney R. H. L. and Boreham P. F. L. (1969). Blood gorged resting blackflies in Cameroon and evidence of zoophily in Simulium damnosum. Trans. Roy. Soc. Trop. Med. Hyg. 63: 286-287.

Dunbar R. W. and Vajime C. G. (1972). The Simulium edwardsellum damnosum complex. A report on cytotaxonomic studies to April 1972. WHO Mimeographed Document. WHO/ONCHO 12 .100 (1972). pp. 1-14.

Freeman P. and de Meillon B. (1968). Simuliidae of the Ethiopian Region. British Musium of Natural History, London.

Gersabeck E. F. and Merrit R. W. (1979). The effect of physical factors on the colonization and relocation behaviour of immature black flies (Diptera: Simuliidae). Environ. Ent. 8: 34-39.

Garms R. and Cheke R. A. (1985) Infections with Onchocerca volvulus in different members of Simulium damnosum complex in Togo and Benin. Zeitschrift fur Angewandte Zoologie 72: 479-95.

Grunewald J. (1981). Hydrochemical and physical characteristics of the larval sites of species of S. damnosum complex. In Black flies: The future for Biological Control Method in Integrated Control. (M. Laird, ed.), pp. 227-235. Academic Press. London.

Le Berre R., Beray G. Breaques J. and Coz J. (1964). Biologique et écologique de la femelle de Simulium damnosum, Theo. 1903, en fonction des zones bioclimatique d'Afrique occidental. Bull. Wld Hlth Org.31: 843-855.

Le Berre R. (1966 ). Contribution à l' étude biologique et écologique de Simulium damnosum Theobald, 1903 (Diptera Simulate) Memoires. O.R.S.T.O.M, Paris.

Opoku A. A. (1997). Some preliminary studies on the biting activity and disease transmission levels of forest Simulium damnosum s.l. in southern Ghana. Ghana J. Sci. 37: 23-31.

Opoku A. A. (2000). Some observation on the ecology, biting activity and parasite infectivity of the Blackfly (Simuliidae) and Onchocerciasis prevalence in River Birim catchment. Ghana J. Sci. 40: 65-73.

Vasjime C. G. and Dunbar R. W. (1975). Chromosomal identification of eight species of the subgenus Edwardsellum near and including Simulium (Edwardsellum) damnosum Theobald (Diptera: Simuliidae). Tropenmedizin und Parasitologie 26: 111138.

Wilson M. D., Cheke R. A., Flasse S. P. J., Grist S., Osei-Atweneboana M. Y., Tetteh-Kumah A., Fiasorgbor G. K., Jolliffe F. R., Boakye D. A., Hougard J. M., Yameogo L. and Post R.J. (2002). Deforestation and the spatio-temporal distribution of savannah and forest members of the Simulium damnosum complex in southern Ghana and south-western Togo. Trans. R. Soc. Trop. Med. Hyg. 96: 632-639. 